\title{
Designing idea processors for document composition
}

\author{
RONALD T. KELLOGG \\ University of Missouri-Rolla, Rolla, Missouri
}

\begin{abstract}
This article details three difficulties encountered during the prewriting and drafting stages of document preparation and describes computer aids designed for each difficulty. Writers experience problems in planning ideas and translating ideas into text because of attentional overload, inability to generate useful ideas, and affective interference. Idea processors are programs that perform various functions to assist with generating and organizing ideas so they can be communicated successfully in a written document. Among other things, an idea processor can serve as a funnel for attention, an inventor of ideas, or therapist for emotional hindrance. The article reviews existing programs that function as funnels, inventors, and therapists and concludes with a discussion of the potential efficacy of such programs in solving the major problems associated with planning and translating.
\end{abstract}

In this paper, I discuss major problems that people experience during the prewriting and drafting stages of document preparation, and describe computer tools, generically called idea processors, that may alleviate these problems. Such work diverges from the mainstream of psychological research on computers. Previous research on human-computer interaction has focused on reducing the complexity of the interface to enhance the usability of the machine. Although improved interface design is a valuable goal for human-computer research, it should not be the only goal. Landauer (1985) recently suggested that psychology might also be fruitfully applied to the problem of conceiving new cognitive tools that might be useful to people. Understanding the limitations facing a person in a specific task, such as composing, and then formulating the type of tools that might aid performance are also important areas for psychological research.

My goals here are (1) to indicate why idea processors are important cognitive tools to be explored as composition aids, (2) to detail three fundamental limitations encountered by even experienced writers during the prewriting and drafting of text, (3) to formulate three relatively novel computer functions that could assist writers, illustrating these with relevant software, and (4) to consider the potential effectiveness of such functions in overcoming the weaknesses of writers.

\section{WHY IDEA PROCESSORS}

Idea processors are programs that assist the writer in generating and organizing ideas or concepts so that they can be communicated successfully to others. Such programs may be useful in several tasks, but the present analysis is limited to the task of planning ideas for a docu-

Reprint requests should be addressed to Ronald T. Kellogg, Department of Psychology, University of Missouri-Rolla, Rolla, MO 65401. ment and translating those ideas into text. Most of the idea processors under consideration are specifically tailored for writing, and writing has been the object of considerable psychological research in recent years.

The processes of prewriting, doing a first draft, and revising subsequent drafts include numerous activities and can require long periods of time to complete. It is useful to categorize these activities as collecting information (reading, listening, and searching bibliographic sources), planning text (creating ideas, organizing ideas, and setting goals), translating plans into text (constructing legitimate sentences-actual language production), and reviewing text (reading, evaluating, editing errors). A well-documented fact is that collecting, planning, translating, and reviewing generally do not occur in a simple linear sequence. Instead, the processes occur recursively during prewriting and on drafts. Detailed theoretical accounts of these processes and evidence on their recursive nature are available from several sources (Beaugrande, 1984; Flower \& Hayes, 1980b; Gould, 1980; Nold, 1981).

Collecting, planning, translating, and reviewing are all amenable to computer assistance (Kellogg, 1985). DIALOG (Seymour, 1984), SCI-MATE (Garfield, 1983), and other bibliographic search systems are widely used tools for collecting information. BOSS (Walker, 1984) and numerous other spelling checkers are growing in popularity as reviewing aids. Writer's Workbench is a versatile tool for reviewing diction, punctuation, read ability, and style, as well as spelling (Macdonald, 1983). In contrast to the relatively abundant selection and common use of tools for collecting and reviewing, tools for planning and translating are few in number and confined in use. Yet tools for planning and translating are clearly needed.

A series of experiments on letter writing (Gould, 1980) indicated that executives spend about two thirds of their 
writing time involved in planning ideas, most of the remaining time translating ideas into text, and relatively little time reviewing what they have written. Other experiments, using different measurement techniques and subjects, indicated that planning and translating combined consume about $75 \%$ of writing time (Kellogg, 1984). Getting started on a draft was reported to be the most difficult part of writing by $30 \%$ of the academic writers surveyed in one study (Green \& Wason, 1982). In the extreme case of a blocked writer, planning and translating are so onerous that few if any words are ever produced for the composer to review (Boice, 1983).

Designing idea processors that effectively aid in the processes of planning and translating requires a theoretical analysis of the writer. Why do adult writers, who possess both the verbal skills and the motivation needed to write acceptable prose, need to invest so much time and effort in planning and translating? The answer may lie in three fundamental limitations of human thinking ability.

\section{FUNDAMENTAL LIMITATIONS}

\section{Attentional Overload}

The first limitation is that writers experience difficulties in planning and translating when they simultaneously attend to reviewing. Limited attentional capacity is overloaded when writers attempt to juggle too many operations. Attention may be divided simultaneously among processes, rapidly alternated among them, or primarily focused on one process while others are executed automatically. Difficulties arise when insufficient time and effort are devoted to planning and translating because of competition from other processes. Effective planning and translation presumably require sustained concentration. Consequently, overloading attention by trying to review at the same time leads to poor planning and translating. This limitation has been discussed in theoretical accounts of composition (Elbow, 1981; Green \& Wason, 1982), and three sources of evidence can be marshaled to support it.

First, verbal protocols of college students thinking aloud while composing reveal the problem of attentional overload (Flower \& Hayes, 1980b). In commenting on their protocol analyses, Flower and Hayes noted that

\footnotetext{
Writing is the act of dealing with an excessive number of simultaneous demands or constraints. Viewed this way, a writer in the act is a thinker on a full-time cognitive overload.... A writer caught in the act looks much more like a very busy switchboard operator trying to juggle a number of demands on her attention and constraints on what she can do. (p. 33)
}

Second, an experiment by Glynn, Britton, Muth, and Dogan (1982, Experiment 1) showed that the quality of planning is adversely affected when writers attempt to translate and review at the same time. They examined the number of arguments generated by students in a persuasive writing task while manipulating via the instructions the number of processes juggled. The unordered- propositions condition encouraged the writers to focus their attention exclusively on generating ideas. The ordered-propositions condition prompted them to generate and organize their ideas. The mechanics-free condition added the requirement of translating their organized ideas into rough-draft sentences. Lastly, the polishedsentences conditions encouraged the students to carefully review their sentences while they were translating and planning. An analysis of the total number of arguments produced on a preliminary draft revealed a significant effect of instructional condition. The means in the four conditions were as follows: polished sentences, 3.3; mechanics-free sentences, 4.9 ; ordered propositions, 8.3 ; unordered propositions, 13.3.

Third, direct measurements of the degree of effort given to planning, translating, and reviewing reveal the demanding nature of these processes. In one experiment (Kellogg, 1986, Experiment 1), I employed directed introspection to track when the writer attended to planning, translating, and reviewing, and secondary-task reaction times to measure the degree of effort given to each process. Collecting was not examined because the subjects were required to write from memory only. In a single sitting, college students wrote a persuasive essay. On a variable-interval schedule, the subjects heard an auditory signal while writing. This was a signal for the subjects to say "Stop"' as quickly as possible, and reaction times were recorded. The subjects were instructed to pay primary attention to their writing and to respond to the signal as rapidly as possible as a secondary task. After saying "Stop," the subjects pressed one of four buttons to indicate whether their thoughts at the moment of the signal reflected planning, translating, reviewing, or some other process unrelated to these. The subjects had been trained to identify their thoughts as belonging to one of these four categories.

The mean reaction times associated with planning, translating, and reviewing were 712,663 , and $705 \mathrm{msec}$, respectively. The mean of baseline reaction times, collected when the subjects were not writing, was $346 \mathrm{msec}$. An analysis of variance revealed that baseline reaction times were significantly less than the times associated with the three writing processes $[F(3,84)=92.56, p<.001]$.

An interference difference score (writing process minus baseline) is an index of how much effort was given to each process: the greater the interference, the more demanding the task. The data for the writing task are plotted on the left side of Figure 1. Planning and reviewing showed the same large expenditure of effort; translating showed significantly less $[F(2,56)=3.64, p<.05]$. To clarify the meaning of these interference scores, it is useful to compare them to those obtained in other experimental tasks. I draw on studies conducted in my laboratory and in other laboratories to make this clear. In all cases, the subject's primary task was complex, involving several cognitive processes, and a rapid, timed response to the primary task was not required. Hence, reaction times to the secondary task reflected the thinking demands of the 


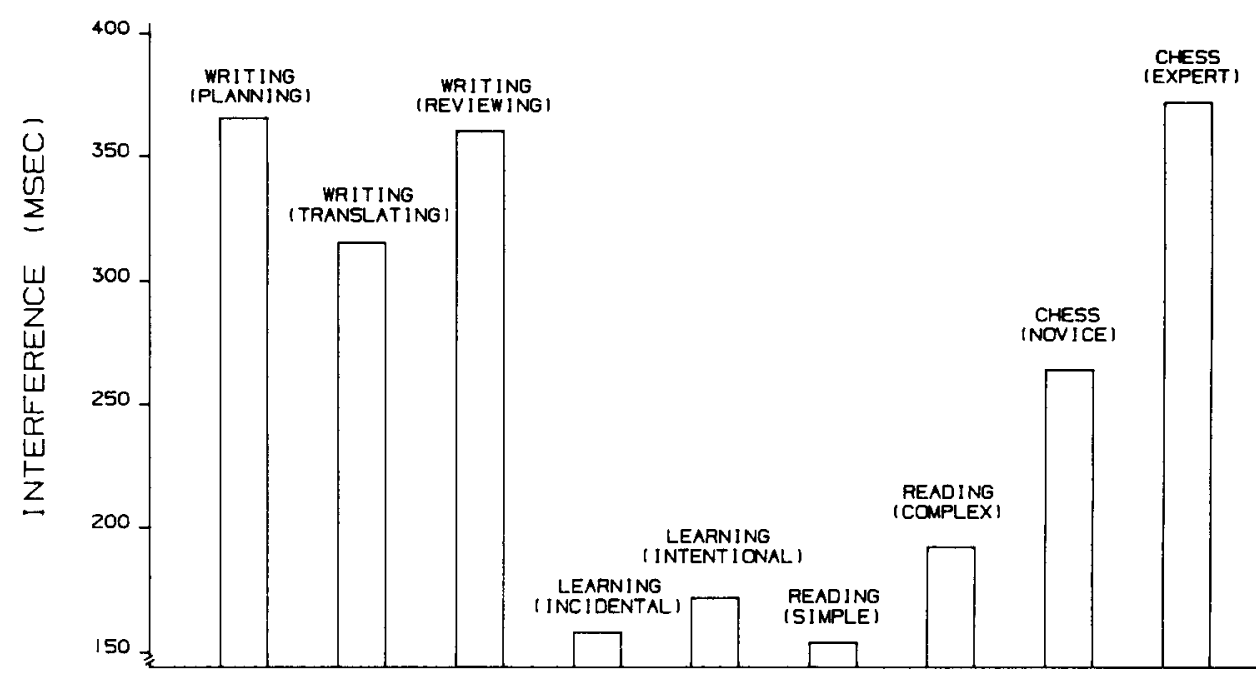

EXPERIMENTAL TASK

Figure 1. Secondary-task reaction time interference for various primary experimental tasks. Writing data are from Kellogg (1986), learning data are from Kellogg (1983), reading data are from Britton, Glynn, Meyer, and Penland (1982), and chess data are from Britton and Tesser (1982).

primary task, rather than rapid response demands. College students served as subjects and an auditory secondary probe was employed in all cases as well. There were minor procedural differences in the studies (e.g., the intensity of the probe), but these factors presumably affected baseline as well as dual task reaction times. By looking at the interference difference scores, it is possible to make comparisons across the various studies (see Figure 1).

In a study of my own (Kellogg, 1983) on learning a list of words, the interference scores for incidental learning and intentional learning instructions were less than half those obtained for the writing processes. Britton, Glynn, Meyer, and Penland (1982) reported relevant data on reading text of varying syntactic complexity; their interference scores both for reading simple syntax and for reading complex syntax were well below those observed for writing processes. Britton and Tesser (1982) examined the effort required to play chess. They had subjects determine the best move to make in several situations taken from the middle stages of an actual game. Their interference scores for novice players were less than, whereas those for expert players were slightly greater than those for writing. Thus, the effort demanded by planning, translating, and reviewing is substantial and is on the order of that required by expert chess play. It is easy to understand, therefore, how attentional overload can occur when the writer tries to juggle all three processes at once.

\section{Idea Bankruptcy}

The second limitation often experienced by writers is a failure to generate usable ideas. Graesser, Hopkinson, Lewis, and Bruflodt (1984) noted that "it is difficult for writers to generate ideas that are informative, interesting, sophisticated, and relevant to a particular pragmatic context" (p. 361). They aptly referred to this difficulty as "idea bankruptcy." This limitation on idea generation is perhaps self-evident to anyone who has tried to compose. It finds strong empirical support in the results reported by Graesser et al. (1984) and in the literature on creativity in problem solving.

Graesser et al. (1984) had college students write papers that exhibited their technical knowledge of economics, cancer, or growing flowers. The students wrote from memory for a reasonably long period of time (a minimum of $25 \mathrm{~min}$ ), under instructions to write down everything that they knew on the topic. For example, the instructions in the economics condition were "Write down all you know about the concept of economics, including inflation, recession, unemployment, and how they are related" (p. 346). Expert judges evaluated each statement on three dimensions (4-point scales). The truth dimension indexed the validity of the statement. The obscurity dimension measured whether the idea was a familiar piece of common knowledge. The sophistication dimension assessed how informative the statement was about relevant processes or mechanisms.

The mean number of statements was surprisingly low for economics $(M=9.6)$ and for growing flowers $(M=$ $11.2)$, and was respectably high for cancer $(M=24.1)$. The overall mean truth score fared well $(M=3.06)$, indicating that most of the statements were true. However, sophistication and obscurity scores were uniformly poor across topics. The mean sophistication score was 2.45 on a 4-point scale, with a value of 1.00 indicating a very uninformative or irrelevant fact. Although most of the students had been exposed to relevant processes and mechanisms in course work, they rarely generated them in this task. The mean obscurity score was 1.61 , with a value 
of 1.00 indicating a very popular or familiar idea (e.g., "Cancer is a disease"). Graesser et al. (1984) summarized their findings as follows: "Most of the generated ideas were true, culturally familiar (that is, not obscure), and unsophisticated" (p. 359).

Another source of evidence for the limitation of idea bankruptcy is the extensive literature on creative problem solving. Preparing a document can be fruitfully viewed as an ill-defined problem consisting of rhetorical, writtenprose, and knowledge subproblems (Flower \& Hayes, $1980 \mathrm{a}, 1980 \mathrm{~b})$. As in solving any problem, people are prone to errors in representing writing problems, searching the problem space for solutions, and evaluating tentative solutions (Hayes, 1981). The literature on creativity tests and on creativity training emphasizes the rarity of individuals who are fluent, flexible, and original in generating ideas (Guilford, 1967; Stein, 1974; Taylor \& Barron, 1963). Such classic impediments as functional fixedness (Duncker, 1945) and persistence of set (Luchins, 1942) undoubtedly contribute to idea bankruptcy in writing tasks. An inability to represent in novel ways objects, events, and concepts relevant to a writing problem might be viewed as a form of functional fixedness. Approaching every writing task in a routinized manner that has seemed to work well in the past illustrates persistence of set.

\section{Affective Interference}

The third limitation experienced by writers is that fears and anxieties can interfere with successful composition. Powerful emotional reactions, both positive and negative, are commonly elicited by the process of writing (Green $\&$ Wason, 1982). These reactions are nicely reflected in a quotation attributed to the novelist James Jones: "I hate writing. I love having written." Lowenthal and Wason (1977) asked academic writers how they felt about the job, and most reported this type of mixed but intense response (e.g., "Writing is a very hard grind-the good times come along only on the back of sweat and tears"). A few found nothing good about the experience (e.g., "Writing is like being sick"), and a few took great pleasure in it (e.g., "Writing is as enjoyable as making love"). Of concern here are the negative affective reactions that lead to procrastination, fretful attempts at writing, and complete avoidance of the task.

How serious is the problem of affective interference? For some writers, the affect spawned by writing may push them beyond the optimum level of arousal for so complex a task. Planning and translating may suffer when arousal levels are too high. If that is so, then writing quality and efficiency should suffer when writing anxieties are too high. Consistent with this expectation, Boice and Johnson (1984) observed a significant negative correlation between reported scholarly productivity and degree of writing anxiety among university faculty. Similarly, Daly (1978) investigated writing apprehension or anxiety among college students by developing an attitudinal questionnaire regarding anxiety and by correlating anxiety with writing performance. He concluded on the basis of several studies that writing-apprehensive students compose poorer quality documents than do less anxious students.

Writer's block occurs when fears and anxieties are so intense that would-be writers fail to begin or continue the process of composition. Rose $(1980,1984)$ found that blocked college students tended to follow rigid, maladaptive rules that disrupted successful writing. For instance, one blocker developed overly elaborate plans that lengthened the prewriting stage to several days. Then, with only a few hours left to create a first draft, the student found it impossible to translate the complex plan into a short essay.

Boice (1985) investigated differences in the self-talk of blockers and nonblockers among university faculty. His subjects recorded on note cards their thoughts during the initiation and completion of writing sessions. Over 5,000 examples of self-talk were collected and categorized. Boice identified seven categories of thoughts: work apprehension, procrastination, dysphoria, impatience, perfectionism, evaluation anxiety, and rules. Work apprehension (thoughts about the difficult, demanding nature of writing) and rules (thoughts about maladaptive formulas for writing, such as "Good writing must be spontaneous and clever") occurred about equally often among blockers and nonblockers. Procrastination (thoughts that justify avoiding or delaying writing) was much more common among blockers (90\%) than among nonblockers $(55 \%)$. Dysphoria (thoughts reflecting burnout, panic, or obsessive worries), impatience (thoughts of achieving more in less time or imposing unrealistic deadlines), perfectionism (thoughts reflecting an internal critic who allows no errors), and evaluation anxiety (thoughts about fears of rejection) also afflicted blockers more than nonblockers.

More evidence of the seriousness of affective interference comes from Kubie's (1958) psychoanalytic treatment of creativity. Kubie challenged the popular belief that neurosis and creativity go hand in hand by describing cases in which creative productivity was diminished because of fear, guilt, and other anxiety states.

How common is emotional hindrance in writing? Procrastination seems to be universal, according to Green and Wason (1982). They found in their surveys of academic writers that getting started is judged to be difficult by all writers and is viewed as the single most difficult part of writing by $30 \%$. Boice and Johnson (1984) found that $34 \%$ of their sample of university faculty reported moderate to high levels of anxiety about writing. A complete writing block, defined as an inability to write for some emotional/motivational reason, was reported by $12 \%$. Rose (1984) reported that about $10 \%$ of the college population are blocked writers. Moreover, Freedman's (1983) survey of college students indicated that $45 \%$ found writing painful, $61 \%$ found it difficult, and $41 \%$ lacked confidence in their ability to write. Affective interference, therefore, seems to be a relatively frequent, as well as serious, difficulty. 


\section{COMPUTER FUNCTIONS}

In this section I describe three relatively novel computer functions that address the fundamental limitations detailed above. Existing programs are categorized as examples of programs that fulfill the function of funnel, inventor, or therapist. My purpose is to review the approaches and methods already taken to achieve these functions, with the hope of stimulating new design research in the area of idea processors for document composition.

\section{Funnel}

To help writers with attentional overload, a computer should serve the function of a funnel. I define a funnel device as an idea processor that channels the writer's attention into only one or two processes. By encouraging the writer to temporarily ignore reviewing and possibly translating, the funnel device might relieve attentional overload. There are several ways to design a funnel device. Currently available funnel devices adopt one of two approaches: distracting information or encouraging free writing (see Table 1). The first approach is seen in programs that allow the writer to expand and collapse an outline and in programs that selectively display the topic sentences of a document.

Outlining software performs the function of a funnel by allowing the writer to construct and retrieve a document at different levels of a hierarchical structure. For instance, to plan the main ideas of a document, without concern for translating or reviewing those ideas, the writer could collapse the outline and display only the superordinate levels of the outline, hiding all subordinate points.
The subordinate points might easily distract the writer from giving full attention to the superordinate levels. Thus, outlining programs explicitly encourage the writer to concentrate only on high-level planning in this example. Alternatively, to focus on translating a specific subordinate idea, the writer could hide all superordinate levels and expand only the subordinate point of interest at the moment. Once a subordinate point is completely translated, it can be selectively displayed for reviewing as well.

Outlining programs do not force the writer to plan first, translate second, and review third, in a linear sequence. On the contrary, they are highly compatible with a recursive strategy of mixing processes in various orders as needed. The writer can certainly shift from, say, reviewing a paragraph stored as a subordinate point to planning a new idea at the highest level of the hierarchy. However, by hiding distracting text, such programs do help the writer to finish reviewing the subordinate point before advancing to planning the new superordinate point.

NLS is an example of a program that expands and collapses outlines (Uhlig, Farber, \& Bair, 1979). It uses an infinitely deep outline structure to organize an evolving text. Each level consists of text ranging in length from a single word to an entire paragraph. The writer develops the outline by adding levels to a hierarchical structure in any manner desired. For instance, the writer might start with three superordinate ideas that are labeled by NLS as 1,2 , and 3 . Next, the writer thinks of a subordinate idea, say, 1A, and then generates another superordinate, 4. Finally, he thinks of a subordinate to idea $1 \mathrm{~A}$, and NLS lables it $1 \mathrm{~A} 1$. The writer can view the outline in different ways, by selectively hiding information. By collapsing and expanding the outline, the writer may more easily focus

Table 1

Idea Processors Serving as Funnel, Inventor, or Therapist

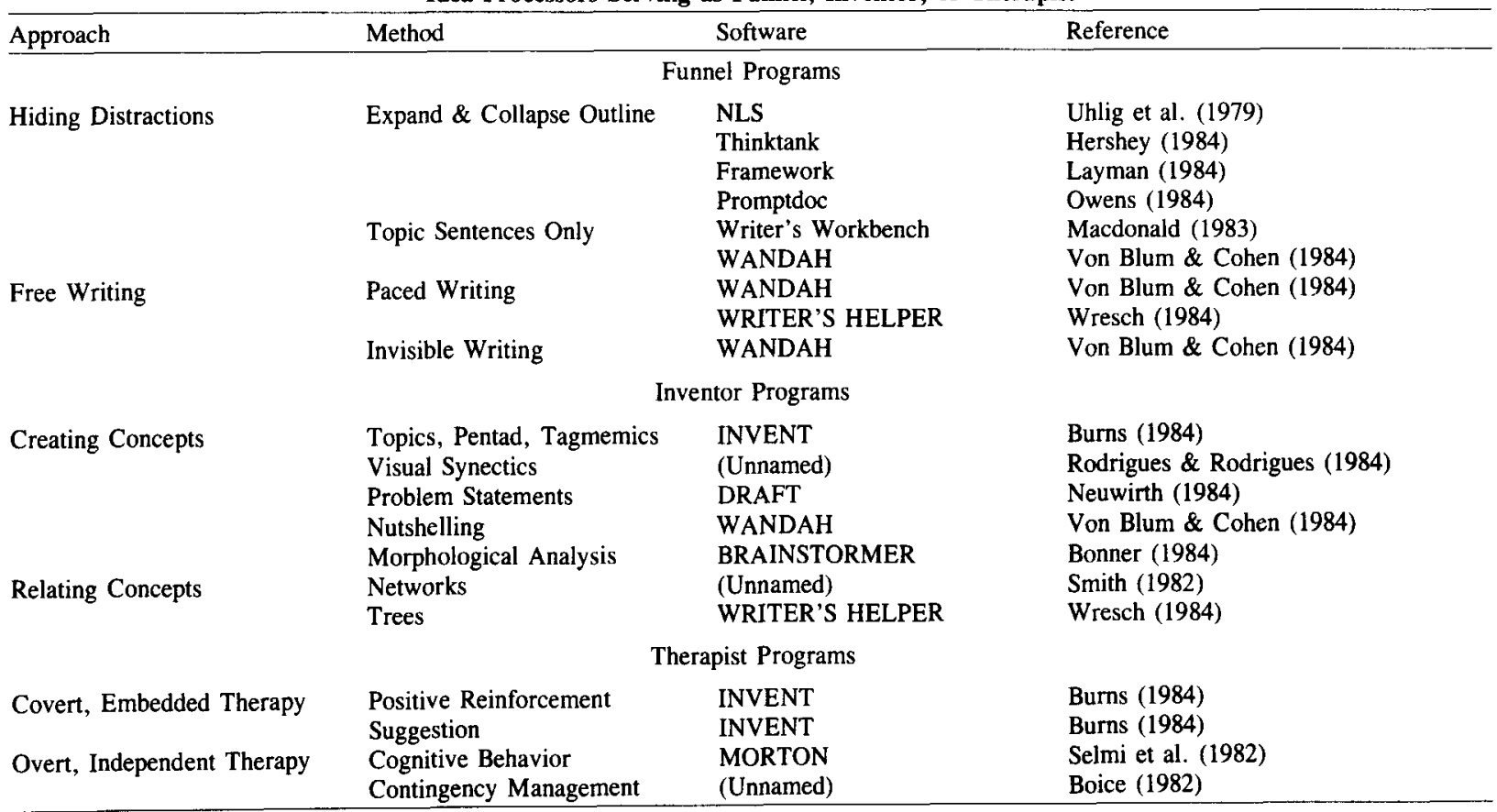


attention on one or two processes at a time. Thinktank (Hershey, 1948), Framework (Layman, 1984), and Promptoc (Owens, 1984) are similar to NLS. Each differs from NLS in the details of how the system numbers the text entries and how the outline is expanded and collapsed.

A second method of hiding distractions is to display only the topic sentence of each paragraph of a document. This method is useful for planning or reviewing the macrostructure of a text while ignoring the details. Writer's Workbench (Macdonald, 1983) displays the first and last sentence of each paragraph. WANDAH (Von Blum \& Cohen, 1984) selects the first sentence or any sentence specifically designated by the writer as a topic sentence.

Free writing refers to rapid translation, following whatever meager plan is available without concern for extensive planning or reviewing (Elbow, 1981). It involves quickly writing off the top of one's head in a freeassociation, stream-of-consciousness manner. The aim of free writing is to put one's thoughts on paper before one's internal editor rejects them as unsophisticated or lacking in style. The product of free writing can and must be scrutinized and edited at a later time. A closely related technique is brainstorming (Flower \& Hayes, 1977), which is more goal directed and less free associational than free writing. In brainstorming, the writer either starts with a plan or develops one while composing, but reviewing is forbidden, as in free writing. Here I use the term free writing to cover both Elbow's (1981) usage of the phrase and the technique of brainstorming.

WANDAH (Von Blum \& Cohen, 1984), a software package designed for university-level writing classes, includes programs that promote free writing. WANDAH encourages free writing by flashing the screen when the writer pauses for too long (long pauses indicate that the writer is planning or reviewing). The flashing serves as a funnel by reminding the writer to focus on translating rapidly. A similar approach is taken in Wresch's (1984) free-writing program that is part of Writer's Helper. His program automatically types a series of Xs if the writer takes more than a second between keystrokes.

Blanking the screen to make the text invisible is another funnel device used by WANDAH to force the writer to ignore reviewing and concentrate on planning and translating. The writer cannot review what he cannot read. The aim of invisible writing is to force the writer to put thoughts on paper without worrying about sentence structure, word choice, and other editing concerns. Although invisible writing precludes reviewing, it does not discourage planning, as the flashing screen method does. However, both invisible writing and the flashing-screen method aim to get the writer not to worry about reading and editing the text as he composes, and this is the essence of free writing as the term is used here.

\section{Inventor}

To assist with idea generation, a computer should serve as an inventor. Programs that attempt to create, clarify, and order a writer's concepts illustrate the inventor role of idea processors. Inventor devices may be divided into those that aid the writer in forming concepts and those that assist with forming relations among previously established concepts (see Table 1). The first approach has been adopted by numerous tutorial programs which were designed to aid students taking college-level rhetoric courses, but could be employed more generally.

Burns $(1979,1984)$ developed INVENT to serve as a prewriting aid; it asks the writer a series of questions about the subject of the document being composed. INVENT includes three types of heuristics in different programs (TOPOI, BURKE, and TAGI) for different types of writing. TOPOI assists with persuasive writing by using Aristotle's 28 enthymeme topics as the basis for asking questions. The topics are categories of arguments that can be applied to any rhetorical problem (Winterowd, 1968). Corbett (1965) explained that the topics were designed for the composer who has no ideas on a subject, only a few underdeveloped ideas, or a large collection of vague ideas. The topics point to the kinds of arguments that flesh out a thesis. For example, the topics include a concern for the meaning of terms (definition and ambiguous terms), similarities and differences (opposites, correlative terms), reasoning procedures (division, induction), and consequences (simple consequences, crisscross consequences).

BURKE helps with informative writing by drawing on Kenneth Burke's dramatistic pentad. The questions concern scene, act, agent, purpose, and agency (Rueckert, 1963). Burke's pentad is a more sophisticated and powerful version of the journalistic pentad who, what, when, where, and why. The information to be conveyed in a document can be regarded as a dramatic act. To develop the document, it is necessary to specify (1) the scene of the act-where, when, and under what circumstances it was performed, (2) the nature and meaning of the act, (3) the agent who performed the act, (4) the purpose of the agent in performing the act, and (5) the agencies or means by which the act was performed. In addition, it is necessary to explore the relationships, called "ratios" by Burke, between particular pairs of elements of the pentad, such as scene and act, agency and act, and purpose and act. Burns's $(1979,1984)$ program is built on 10 such ratios.

TAGI aids informative writing by employing the tagmemic matrix of Young, Becker, and Pike (1970). TAGI's questions prompt the writer to see a concept to be included in a document from three perspectives. The concept can be viewed as a particle (as if it were static), as a wave (as if it were dynamic), or as a field (as if it were part of a larger network). These questions follow from only part of the theory proposed by Young, Becker, and Pike. The complete tagmemic matrix consists of nine cells. The rows represent the perspectives of particle, wave, and field. The columns represent three features of any concept to be communicated, namely, its contrastive features (how it differs from other concepts), its range 
of variation (how it can vary and still remain the same concept), and its distribution in larger contexts (how it fits into a larger system).

To illustrate how these programs operate, consider this brief segment of an actual run of TOPOI (Burns \& Culp, 1980 , p. 8; student input is in italics):

During this exploration process, you will be asked to clarify the purpose of your paper on fear of death.

So now would you briefly describe the purpose of your paper by completing this statement: The purpose of this paper is to ...

Examine the fear of death people have, where we get those fears, and how we may reduce those fears.

Fine, Walt, you and I will talk again about your purpose. Relax now, Walt, and enjoy this brainstorming session. What objects do you associate with fear of death?

How might they be included in your theme?

Fear of the unknown, cessation of life, fear of causing pain to our loved ones.

That's the idea, Walt. Give me some more info now.

Pain is another fear causer, knowing we have to die does not relieve the pain/fear of dying.

Super, Walt!

Anything else?

(You can add more info, ask a question, or give a command-whatever you wish.)

How does euthanasia, mercy killing, suicide, murder, and accidental death add to our fears?

I could say that that's for me to know and for you to find out.

Seriously, I cannot pretend to know 'how,' but you should keep exploring for an answer.

Continue!

(Try explaining a little more, less phrases, more sentences.) We're moving right along. Here is Question 2.

What could be considered a result of fear of death?

Nervousness, depression, suicidal tendencies.

By George, Walt, good one. Write a little more, please.

Hatred for the person who caused the death, or the person who died.

Fantastic, Walt! anything else?

\section{Continue!}

Okay.

Do you wish to narrow or change your subject?

(Maybe revise the way it sounds in these questions?) (Yes or No?)

Visual synectics is a creative invention heuristic based on drawing analogies between the subject being written about and other seemingly unrelated visual concepts. As with any synectics approach, the aim is to spur creativity by forcing the writer to consider nonobvious relationships (Gordon, 1961). Rodrigues and Rodrigues (1984) described a tutorial program (unnamed) that uses visual synectics. The program first asks the student to name the writing subject. The student then examines a graphic display or a photograph selected from a collection prepared by the instructors. The program asks the writer to describe objects present in the picture. After eliciting a list of 5 to 10 objects, the program asks the writer to compare the subject to each item on the list. The purpose of visual synectics is to elicit novel views of the subject, views the student might never think of without drawing analogies. Rodrigues and Rodrigues (p. 37) gave the illustration of a student writing on nuclear waste disposal who compared the subject to a beachball ("On the surface, the plans seem solid, but there is a lot of hot air underneath that surface") and to a bathing suit ("We may discover that it offers us very little protection"').

Related methods for forming concepts are problem statements, nutshelling, and morphological analysis. Young, Becker, and Pike (1970) developed heuristic questions for developing problem statements or for clarifying the subject of the document; these are embodied in Neuwirth's (1984) DRAFT program. Examples of these questions are "What is the problem?" and "Are the components of the problem clearly dissonant or incompatible?" Nutshelling is a heuristic developed by Flower (1981) for forming concepts about the rhetorical problem facing the writer. WANDAH (Von Blum \& Cohen, 1984) employs nutshelling by asking the writer to state the purpose of and the intended audience for the paper and to provide a synopsis of its main ideas. In short, the writer is asked to "put it in a nutshell."' Morphological analysis is a heuristic for forming new concepts through a dimensional analysis of old concepts (Stein, 1974). BRAINSTORMER (Bonner, 1984) guides the writer to think of the dimensional structure of two or more concepts concerning the writing subject. The program then establishes a multidimensional matrix of these old concepts. New concepts may be formed through interesting, novel combinations of these dimensions.

A second type of inventor program aims to clarify and order ideas by forming relations among concepts. Smith (1982) described a program (unnamed) that uses a network method to form relations. The program first asks the writer to list the ideas to be included in the text. Then the program presents all possible pairs of ideas, one at a time, and asks the writer if the pair is related. If the answer is yes, the writer is asked to specify the nature of the relation. The program can assist the writer in this by displaying a menu of possible relations (e.g., "is an explanation of," "is analogous to"). After the relations are specified, the program displays in a graphical network each idea as a node, the links among nodes, and a label indicating the type of relation for each link.

A similar program, based on tree structures rather than networks, is called TREE and is part of WRITER'S HELPER (Wresch, 1984). The program asks the writer for a list of ideas and then guides the writer in finding the hierarchical-category relationships among the ideas. After developing the hierarchy, the program displays the resulting tree structure.

\section{Therapist}

To deal with affective problems connected with writing, the computer should serve as a therapist. Idea proces- 
sors that try to reduce the anxiety, frustration, and lack of confidence of the writer serve the therapist function. One way to accomplish this function is to embed therapy within an idea processor whose primary function is to serve as a funnel or an inventor. The therapy delivered in this embedded fashion is covert, in the sense that the writer is not turning to the program primarily for therapy.

To illustrate, INVENT (Burns, 1984; Burns \& Culp, 1980) positively reinforces the writer by using terms such as "good," "fine," "terrific," and "that's the idea" in response to the writer's input. It also makes suggestions to the writer that are primarily affective, not cognitive (e.g., " Relax now and enjoy this brainstorming session", and "We'll have a good time thinking about _-..-."). Thus, while employing Aristotle's topics as an invention heuristic, the writer covertly receives therapy to alleviate anxiety and build confidence. Positive reinforcement and suggestions of positive affect could be embedded in outlining, free-writing, and other types of idea processors. INVENT seems to be the only extant example of an embedded, covert therapist device.

Alternatively, it is possible to design an overt, independent therapist program that the writer uses with the intention of receiving therapy. Neumann (1986) described several programs that implement specific therapeutic techniques and some of the advantages of such programs over human therapists. For instance, MORTON is a program that delivers Beck's cognitive-behavioral therapy to depressed individuals (Selmi, Klein, Greist, Johnson, \& Harris, 1982). Unlike human therapists, MORTON is available any time the user wants it and never gets bored, tired, or angry with the user. As a therapist for writers, MORTON would obviously be most appropriate for those who are depressed. However, because a main tenet of cognitive therapy is the alteration of debilitating and selfdefeating thought patterns, it could perhaps be tailored to deal with procrastination, dysphoria, evaluation apprehension, and other symptoms expressed in the self-talk of blocked writers (Boice, 1985).

Although I know of no currently available program, behavioral therapy is another viable method for implementing a therapist device. Reports of success in treating blocked writers with behavioral therapy (Boice, 1982, 1983; Rosenberg \& Lah, 1982) indicate that contingencymanagement software for writers might be worth developing. Such software could be programmed to set up a time schedule for completing the document, monitor the number of words produced per writing session, and deliver verbal reinforcers.

\section{Other Points About Functions}

I regard the funnel, inventor, and therapist functions as the most novel and interesting ways in which idea processors can facilitate planning and translating for writers. But these are obviously not the only such functions. Software can rapidly compute numerical (spread sheets), pictorial (graphics), and linguistic (word processing) information, freeing the writer from the drudgery of doing so. Also, software can store (word processing) and retrieve (text base search) notes, sources, and other information needed by writers. Computation and memory aiding are already well-accepted and appreciated functions. Hence, there seems little point in dwelling on them here.

I have discussed the funnel, inventor, and therapist functions as if each program carried out a single function. INVENT illustrates the point that a single program can combine functions (in this case, the functions of inventor and therapist). I assume that the most effective idea processor will be one that integrates all functions. Designing a workable human-machine interface for such an integrated idea processor raises numerous problems that are beyond the scope of the present article. Assuming such an integrated program could be designed, just how effective would it be in helping writers to plan and translate text?

\section{POTENTIAL EFFICACY}

Idea processors are still in their infancy. It would be premature to pronounce firm judgments about the efficacy of any of the programs discussed here in helping writers with planning and translating. At this time it is appropriate to address the types of research that are needed, the variables that are likely to be important, and the central theoretical issue that may constrain the effectiveness of idea processors.

\section{Types of Research}

With one exception, there appear to be no evaluation studies in the literature. The exception is Burns's (1979) dissertation on INVENT. He compared three experimental groups, in which students employed TOPOI, BURKE, and TAGI, with a control group, in which students heard a lecture on the creative process. Burns took several measures of the quality of the students' prewriting inquiry and then of their composition plan (e.g., a detailed outline); the students did not compose a draft for evaluation. He found that all three experimental groups significantly outperformed the control group in terms of the number of ideas generated, the factuality, surprise value, insightfulness, and comprehensiveness of those ideas, and in the evidence of intellectual processing and overall quality impression of their prewriting inquiry. No significant differences were found on any of these measures among the experimental groups. The quality of composition plans was statistically equivalent for all four groups on all measurements taken. Thus, the benefits seen in the prewriting phase did not carry over to the phase of arranging a plan for a first draft. The attitudes of students toward using the programs were positive. They believed the programs helped them to think and that the heuristics would be useful for many types of writing assignments. More research like Burns's program evaluation needs to be conducted if conclusions about the efficacy of idea processors are to be drawn.

However, considerable conceptual design work is needed before concentrating purely on specific program 
evaluation, or even program development. The problem is that the best approaches and methods for implementing the funnel, inventor, and therapist functions are unknown. Extant idea processors are based on the conjecture, rather than the fact, that particular methods are powerful controllers of human cognition. For instance, Burns selected Aristotle's topics, Burke's pentad, and Young, Becker, and Pike's tagmemic matrix from a sizeable collection of rhetorical invention heuristics on the basis of Lauer's (1967) theoretical evaluation of the available heuristics. Burns chose the three that theoretically are the most powerful, fully recognizing that empirical validation is necessary. Paper and pencil tests should perhaps be used to determine which invention heuristics merit the expense of program development. Research on approaches and methods of implementing the funnel and therapist functions is also lacking. Such work should specify how to design idea processors for specific types of writers, writing tasks, and writing performance objectives.

\section{Types of Writers, Tasks and Performance Measures}

A likely outcome of future research on idea processors will be the establishment of boundary conditions on their usefulness. The effectiveness of particular programs will depend on the characteristics of the writer, the writing task, and the performance measure examined. A writer's personality and method of composing may in part determine the usefulness of a particular program. For instance, free-writing programs may have the effect of flustering, rather than freeing, individuals who find it very difficult to ignore reviewing while planning and translating. A perfectionist who insists on trying to compose a polished first draft may be the most in need of free-writing programs and the least able to benefit from them. Similarly, some individuals may prefer the discreetness and anonymity of receiving therapy from a computer, whereas others may regard machines as too impersonal to be of any use. Bridwell, Johnson, and Brehe (in press) reported substantial individual differences in the ease with which writers can compose on a word processor. Related differences for idea processors are likely to emerge.

Throughout this article, I have treated writing as if it were a uniform task. Of course, it is not. Scientific, technical, business, journalistic, fictional, and poetic writing, for example, each carry their own unique requirements for being informative, persuasive, and entertaining. Certain inventor devices intuitively seem best suited for particular types of writing, such as Aristotle's topics for persuasive writing and visual synectics for poetry or short stories. In contrast, funnel and therapist devices may work equally well across various writing tasks. Determining the range of applicability of specific idea processors is an important goal for future research.

Lastly, whether an idea processor is effective undoubtedly depends on how effectiveness is measured. Broadly speaking, writing performance can be measured in terms of efficiency and quality. Efficiency refers to the amount of time and effort needed to produce a document. Total time to compose and words composed per minute are examples of efficiency measurements. Quality refers to how effectively a document communicates, and is difficult to quantify (Hirsch \& Harrington, 1981). Although no single technique is ideal, the following methods can be employed: holistic judgments of the document (Charney, 1984); judgments of specific features, such as idea development (Atlas, 1979); and calculations of readability based on standard formulas (Klare, 1976). Funnel and therapist devices should have their greatest impact on a writer's efficiency. They seem best suited for reducing the time and effort needed to prepare a document. In contrast, inventor devices should influence the quantity and quality of ideas generated by a writer (see Burns, 1979).

\section{Specific Knowledge Versus General Methods}

Although firm conclusions about efficacy are premature, one overarching theoretical controversy surrounding idea processors must be noted. An assumption underlying the use of idea processors is that writers can benefit from the application of general methods of solving problems. Funneling attention to one or two processes, using invention heuristics, and reducing debilitating anxiety are general problem-solving methods that apply across many domains and tasks. If the role of domain- and taskspecific knowledge overshadows the role of general methods in writing performance, then idea processors may contribute very little.

Acquiring extensive relevant knowledge about one's language, writing topics, and prospective audiences-and practicing the task of writing for several thousands of hours-may not eliminate writing difficulties, but such expertise should certainly lessen their severity. First, the experienced writer can better handle multiple processes simultaneously, because some aspects of the task are automatically performed. The expert writer may find it possible to concentrate on planning and translating while reviewing automatically, for instance. Dorothy Parker (in Cowley, 1958, p. 10) and William Zinsser (1983), both highly accomplished writers, claimed that they carefully constructed every word, phrase, and sentence as they composed a first draft, enabling them to produce a highly polished piece. Extensive knowledge is undeniably a useful resource for generating good ideas. Hayes (1981) reported that the most creative works of musical composers came only after at least 10 years of intensive study and preparation in the art of composing. This was so even for child prodigies such as Mozart. Lastly, extensive practice at the job of writing-knowing full well the ups and downs to be expected-may help with the problem of emotional hindrance. Having successfully handled procrastination, evaluation anxiety, and other emotional difficulties could prepare the writer for coping with affective interference in the future. 
The degree to which general methods add to the contribution of specific knowledge is unclear in the case of writing. The broader issue of how skilled thinking-of which writing is one example-depends on the relative contribution of specific knowledge versus general methods is currently a contested and central issue in cognitive science and engineering (Glaser, 1984; Sternberg, 1985). Designing and evaluating idea processors may be a fruitful way to address this important question.

\section{REFERENCES}

AtLAS, M. (1979, December). Addressing an audience: A study of expertnovice differences in writing. (Report No. 3). New York: American Institutes for Research.

Beaugrande, R. DE (1984). Text production. Norwood, NJ: Ablex.

BoICE, R. (1982). Increasing the writing productivity of "blocked" academicians. Behavior Research \& Therapy, 20, 197-207.

BoICE, R. (1983). Clinical and experimental treatments of writing block. Journal of Consulting \& Clinical Psychology, 51, 183-191.

BoICE, R. (1985). Cognitive components of blocking. Written Communication, 2, 91-104.

Borce, R., \& Johnson, K. (1984). Perception and practice of writing for publication by faculty at a doctoral-granting university. Research in Higher Education, 21, 33-43.

Bonner, P. (1984, March). Make a new plan, Stan. Personal Software, pp. 120-123.

Bridwell, L., Johnson, P., \& Brehe, S. (in press). Composing and computers: Case studies of experienced writers. In A. Matsuhashi (Ed.), Writing in real time: Modelling production processes. London: Longman.

Britton, B. K., Glynn, S. M., Meyer, B. J. F., \& Penland, M. J. (1982). Effects of text structure on use of cognitive capacity during reading. Journal of Educational Psychology, 74, 51-61.

BritTon, B. K., \& TESSER, A. (1982). Effects of prior knowledge on use of cognitive capacity in three complex cognitive tasks. Journal of Verbal Learning \& Verbal Behavior, 21, 421-436.

BuRNs, H. (1979). Stimulating rhetorical invention in English composition through computer-assisted instruction. Dissertation Abstracts International, 40, 3734A. (University Microfilms No. 79-28268)

BURNs, H. (1984). Recollections of first-generation computer-assisted prewriting. In W. Wresch (Ed.), The computer in composition instruction. Urbana, IL: National Council of Teachers of English.

Burns, H. L., \& CulP, G. H. (1980, August). Stimulating invention in English composition through computer-assisted instruction. Educational Technology, pp. 5-10.

CharNey, D. (1984, February). The validity of using holistic scoring to evaluate writing: A critical overview. Research in the Teaching of English, pp. 65-81.

CorbetT, E. P. J. (1965). Classical rhetoric for the modern student. New York: Oxford University Press.

COWLEy, M. (Ed.). (1958). Writers at work: The Paris Review interviews (Vol. 1). New York: Viking.

DALY, J. A. (1978). Writing apprehension and writing competence. The Journal of Educational Research, 2, 10-14.

DunCKer, K. (1945). On problem solving (L. S. Lees, Trans.). Psychological Monographs, 58(Whole No. 270).

ELBow, P. (1981). Writing with power. New York: Oxford University Press.

FLOWER, L. S. (1981). Problem-solving strategies for writing. New York: Harcourt Brace Jovanovich.

Flower, L. S., \& HAYES, J. R. (1977). Problem-solving strategies and the writing process. College English, 39, 449-461.

FLoWER, L. S., \& HAYES, J. R. (1980a). The cognition of discovery: Defining a rhetorical problem. College Composition \& Communica tion, 2, 21-32.

Flower, L. S., \& Hayes, J. R. (1980b). The dynamics of composing:
Making plans and juggling constraints. In L. W. Gregg \& E. R. Steinberg (Eds.), Cognitive processes in writing (pp. 31-50). Hillsdale, NJ: Erlbaum.

Freedman, S. W. (1983). Student characteristics and essay test writing performance. Research in the Teaching of College English, 17, 313-325.

GARFIELD, E. (1983, April 4). Introducing SCI-MATE-a menu-driven microcomputer software package for online and offline information retrieval. Current Contents, pp. 5-15.

GLASER, R. (1984). Education and thinking: The role of knowledge. American Psychologist, 39, 93-104.

GlynN, S. M., BRItTon, B. K., MUTh, D., \& Dogan, N. (1982). Writing and reviewing persuasive documents: Cognitive demands. Journal of Educational Psychology, 74, 557-567.

GoRDON, W. J. J. (1961). Synectics. New York: Harper \& Row.

GouLD, J. D. (1980). Experiments on composing letters: Some facts, some myths, and some observations. In L. W. Gregg \& E. R. Steinberg (Eds.), Cognitive processes in writing (pp. 97-127).

Graesser, A. C., Hopkinson, P. L., Lewis, E. W., \& Bruflodt, H. A. (1984). The impact of different information sources on idea generation: Writing off the top of our heads. Written Communication, 1, 341-364.

GreEN, D. W., \& Wason, P. C. (1982). Notes on the psychology of writing. Human Relations, 35, 47-56.

GUILFORD, J. P. (1967). The nature of human intelligence. New York: McGraw-Hill.

HAYES, J. R. (1981). The complete problem solver. Philadelphia: Franklin Press.

Hershey, W. R. (1984, May). Thinktank: An outlining and organizing tool. Byte, pp. 189-194.

HirsCh, E. D., JR., \& Harrington, D. P. (1981). Measuring the communicative effectiveness of prose. In C. H. Frederiksen \& J. F. Dominic (Eds.), Writing: Process, development, and communication (Vol. 2, pp. 189-208). Hillsdale, NJ: Erlbaum.

KellogG, R. T. (1983) [Cognitive effort in intentional and incidental learning]. Unpublished raw data.

Kellogg, R. T. (1984, November). Cognitive strategies in writing. Paper presented at the meeting of the Psychonomic Society, San Antonio, TX.

KelloGg, R. T. (1985). Computer aids that writers need. Behavior Research Methods, Instruments, \& Computers, 17, 253-258.

KELLOGG, R. T. (1986). Effects of topic knowledge on the allocation of time and effort to writing processes. Manuscript submitted for publication.

KLARE, G. R. (1976). A second look at the validity of readability formulas. Journal of Reading Behavior, 8, 129-152.

KuBIE, L. S. (1958). Neurotic distortion of the creative process. Lawrence, KS: University of Kansas Press.

Landauer, T. K. (1985). Psychological research as the mother of invention. In L. Borman \& B. Curtis (Eds.), Proceedings of CHI '85, Human Factors in Computing Systems (pp. 1-10). New York: Association for Computing Machinery.

LAUER, J. M. (1967). Invention in contemporary rhetoric: Heuristic procedures. Dissertation Abstracts International, 28, 5060A. (University Microfilms No. 68-7656)

LaYman, D. (1984, August 7). Framework: An outline for thought. PC Magazine, pp. 119-127.

LowenthaL, D., \& Wason, P. C. (1977, June 24). Academics and their writing. London Times Literary Supplement, p. 282.

Luchins, A. S. (1942). Mechanization in problem solving. Psychological Monographs, 54(Whole No. 248).

MacDonald, N. H. (1983). The UNIX Writer's Workbench software: Rationale and design. Bell System Technical Journal, 62, 1891-1908. Neumann, D. (1986). A psychotherapeutic computer application: Modification of technological competence. Behavior Research Methods, Instruments, \& Computers, 18, 135-140.

NeUwirth, C. M. (1984). Toward the design of a flexible, computerbased writing environment. In W. Wresch (Ed.), The computer in composition instruction. Urbana, IL: National Council of Teachers 
of English.

NolD, E. W. (1981). Revising. In C. H. Frederiksen and J. F. Dominic (Eds.), Writing: Process, development, and communication (Vol. 2, pp. 67-80). Hillsdale, NJ: Erlbaum.

OWens, P. (1984, April). Thinktank and Promptdoc. Popular Computing, pp. 186-189.

Rodrigues, D., \& Rodrigues, R. J. (1984). Computer-based creative problem solving. In W. Wresch (Ed.), The computer in composition instruction. Urbana, IL: National Council of Teachers of English.

RosE, M. (1980). Rigid rules, inflexible plans, and the stifling of language: A cognitivist's analysis of writer's block. College Composition \& Communication, 31, 389-401.

Rose, M. (1984). Writer's block: The cognitive dimension. Carbondale, IL: Southern Illinois University Press.

RosenberG, H., \& LAH, M. I. (1982). A comprehensive behavioralcognitive treatment of writer's block. Behavioral Psychotherapy, 10, 356-363.

RUECKERT, W. H. (1963). Kenneth Burke and the drama of human relations. Minneapolis: University of Minnesota Press.

Selmi, P. M., Kiein, M. H., Greist, J. H., Johnson, J. H., \& HaRRIS, W. G. (1982). An investigation of computer-assisted cognitivebehavior therapy in the treatment of depression. Behavior Research Methods \& Instrumentation, 14, 181-185.

SeYmour, J. (1984, September). Data bases: Managers go on-line. Today's Office, pp. 36-40.
Smith, R. N. (1982). Computerized aids to writing. In W. Frawley (Ed.), Linguistics and literacy (pp. 189-208). New York: Plenum. Stein, M. I. (1974). Stimulating creativity: Vol. 1. Individual procedures. New York: Academic Press.

STERNBerg, R. J. (1985). All's well that ends well, but it's a sad tale that begins at the end: A reply to Glaser. American Psychologist, $\mathbf{4 0}$, 571-572.

TAYLOR, C. W., \& BARRON, F. (Eds.). (1963). Scientific creativity: Its recognition and development. New York: Wiley.

UhLIG, R. P., FARBER, D. J., \& BAIR, J. H. (1979). The office of the future. Holland: Elsevier North-Holland.

Von Blum, R., \& CoHEn, M. E. (1984). WANDAH: Writing aid and author's helper. In W. Wresch (Ed.), The computer in composition instruction. Urbana, IL: National Council of Teachers of English. WALKER, L. (1984, April). How to polish up your word processing. Personal Software, pp. 108-115, 156-157.

WINTERowD, W. R. (1968). Rhetoric: A synthesis. New York: Holt, Rinehart \& Winston.

WRESCH, W. (1984). Questions, answers, and automated writing. In W. Wresch (Ed.), The computer in composition instruction. Urbana, IL: National Council of Teachers of English.

Young, R. E., Becker, A. L., \& Pike, K. L. (1970). Rhetoric: Discovery and change. New York: Harcourt Brace Jovanovich.

Zinsser, W. (1983). Writing with a word processor. New York: Harper \& Row. 